\title{
Association between speech and dental occlusion changes in children with cleft lip and palate and time of primary plastic surgeries
}

\author{
Gabriela Ribeiro Schilling ${ }^{1}$ \\ https://orcid.org/0000-0002-9403-1996 \\ Maria Cristina de Almeida Freitas Cardoso ${ }^{1}$ \\ https://orcid.org/0000-0002-0954-8174 \\ Paulo Sérgio Gonçalves da Silva ${ }^{2}$ \\ https://orcid.org/0000-0002-2746-7298 \\ Marcia Angélica Peter Maahs ${ }^{1}$ \\ https://orcid.org/0000-0002-9212-6422
}

Universidade Federal de Ciências da Saúde de Porto Alegre - UFCSPA, Porto Alegre, Rio Grande do Sul, Brasil. Pontifícia Universidade Católica do Rio Grande do Sul, Hospital São Lucas, Porto Alegre, Rio Grande do Sul, Brasil.

Conflict of interests: Nonexistent

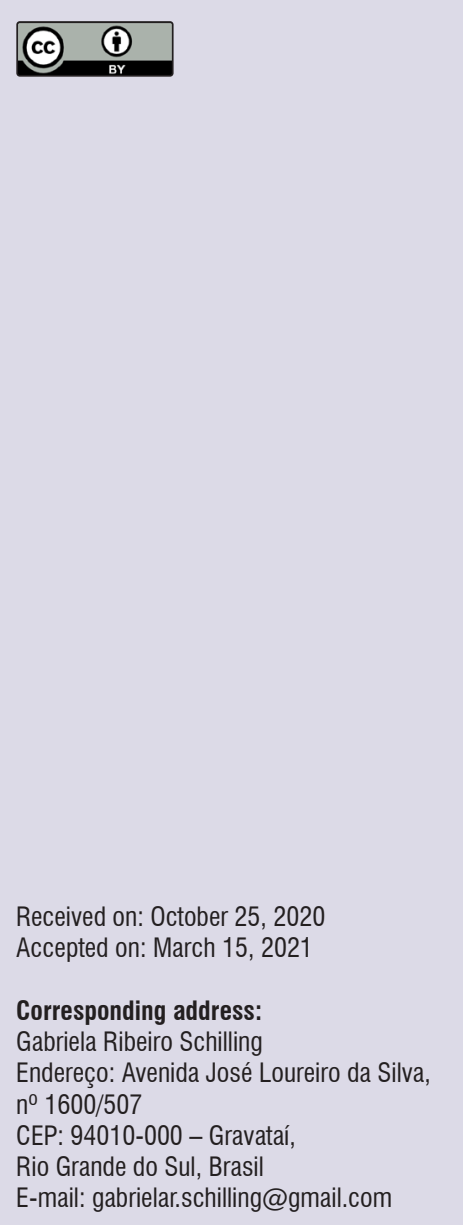

\section{ABSTRACT}

Purpose: to describe the changes in speech and dental occlusion in children with cleft lip and palate and verify their association with each other and with the time of primary plastic surgeries.

Methods: a cross-sectional study with collected data on the subjects' identification, age at the time of primary surgeries, and clinical assessment of speech and dental occlusion. The chi-square test, Fisher's exact test, and t-test were used to verify the associations between the variables at the $5 \%$ significance level $(p<0.05)$.

Results: the sample comprised 11 children aged 6 to 10 years, most of whom were males, self-reported white, with trans-incisive foramen cleft, predominantly on the left side. The mean age at lip repair surgery was 6 months, and 13 months at palatoplasty. Among the main dental occlusion changes, posterior and anterior crossbite stood out. All the subjects presented changed speech, with a prevalence of cases with dentoalveolar and palatine deformities, followed by passive and active changes. Subjects with anterior crossbite tended to have undergone primary lip repair surgery at a mean of four months earlier than the subjects without anterior crossbite.

Conclusions: the associations between speech and dental occlusion changes, and between these and the time of primary plastic surgeries were not statistically significant. Even though it is known that early lip repair surgery is ideal to favor oral functions and aesthetics, the results revealed a tendency towards anterior crossbite, in these subjects.

Keywords: Cleft Lip; Cleft Palate; Plastic Surgery; Speech, Language and Hearing Sciences; Orthodontics 


\section{INTRODUCTION}

The cleft lip and palate (CLP) condition is among the most common congenital facial malformations. It is caused by the incomplete fusion of the palatine processes while still in the intrauterine life 1 . Its prevalence is approximately 1 per every 1,000 live births in Brazil, with variations depending on the Brazilian region being studied ${ }^{2,3}$. As for cleft laterality, it occurs more frequently on the left side; also, there is a greater prevalence of trans-incisive foramen cleft among males, while post-incisive foramen clefts are more prevalent among females ${ }^{2,4}$.

Subjects with CLP must be submitted to surgical procedures to repair the lips (lip repair surgery), the palate (palatoplasty), or both while still a baby to favor oral functions ${ }^{5,6}$. The age when these procedures take place can influence these subjects' speech acquisition process, as well as the conformation of the upper dental arch and the transversal and anteroposterior measurements of the maxilla ${ }^{6-8}$. Palatoplasty is considered early between 12 and 18 months, and lip repair, between 3 and 6 months, according to the Craniofacial Anomalies and Rehabilitation Hospital of the Universidade de São Paulo (University of São Paulo) ${ }^{9}$. Early lip repair reduces the extension of the cleft and provides better aesthetics and quality of life. On the other hand, it restricts the anterior growth of the maxillary $\operatorname{arch}^{10}$. Early palatoplasty favors a better speech profile ${ }^{11}$, although it can inhibit the maxillary growth, with consequences to dental occlusion ${ }^{7,11}$.

The speech-language-hearing changes found in subjects with CLP are related to the fields of voice, speech, and language ${ }^{12,13}$. The changes in producing speech sounds may be due to dental changes, alveolar or palatine deformities, velopharyngeal insufficiency or incompetence, resonance changes, weak intraoral pressure, nasal emission, speech intelligibility changes, compensatory articulation disorders, and so forth ${ }^{12-14}$. Dental occlusion changes, such as crossbite, maxillary protrusion or retrusion, dental failures, rotation of anterior teeth, and ectopic teeth, can lead to changes in speech, especially of the alveolar consonants ${ }^{12}$. The severity of the changes in speech varies greatly; it can even reach a degree of unintelligibility that impairs the subject's social interaction ${ }^{14}$.

Dental agenesis, radicular dilaceration, microdontia, and tooth rotation on the same side of the cleft are commonly found in subjects with CLP ${ }^{4,15}$. The severity of these dental anomalies is related to the severity of the cleft ${ }^{15}$. The subjects with CLP frequently have anterior crossbite (ACB), posterior crossbite (PCB), and changes in number, size, shape, and position of the teeth ${ }^{4,10,15,16}$.

This study aimed to describe the speech and dental occlusion changes in children presented with cleft lip and palate, and verify their association with each other and with the time of primary lip and palate plastic repair surgeries.

\section{METHODS}

This was a cross-sectional study, approved by the Research Ethics Committee (REC) of the Hospital da Criança Santo Antônio (Santo Antônio Children's Hospital - HCSA) under evaluation report number 2575165 and the Pontifícia Universidade Católica do Rio Grande do Sul (Pontifical Catholic University of Rio Grande do Sul - PUCRS), Brazil, under evaluation report number 3262388 . The data collection and assessments took place at the outpatient centers of the public health care system (SUS, in Portuguese), at the Cleft Lip and Palate Rehabilitation Center (CERLAP) of the Hospital São Lucas at PUCRS, and at the HCSA, in the Complexo Hospitalar Santa Casa de Misericórdia of Porto Alegre, RS, Brazil. This last hospital, the Holy House of Mercy, is where the "Cleft Lip and Palate" outreach program is developed as part of the Speech-Language-Hearing Program at the Universidade Federal de Ciências da Saúde de Porto Alegre (Federal University of Health Sciences of Porto Alegre - UFCSPA).

The analysis was conducted with data obtained from the medical records of subjects who met the inclusion criteria and attended the visit during data collection. The inclusion criteria encompassed having CLP corrected with lip repair surgery, palatoplasty, or both; being 6 to 12 years old; being a patient at one of the services (HCSA or CERLAP/PUCRS). The exclusion criteria encompassed being diagnosed with neurological syndromes or diseases, related or not to the cleft; having a history of facial traumas; having a cognitive impairment that hindered the assessment; having undergone orthodontic treatment; and having been discharged from the speech-language-hearing treatment after concluding speech therapy. The adults responsible for the subjects included in this research signed the informed consent form and the photograph consent form; also, the literate subjects signed the minor's assent form. Hence, all of them authorized the data and images to be used.

The anamnesis was conducted with the adults responsible for the subjects of this study. They informed 
the identification data, classification of the cleft, type and date of the primary corrective plastic surgeries, presence of a fistula, and other therapeutic interventions to which they had been submitted.

The speech was collected using the speech assessment of the lingual frenulum evaluation protocol ${ }^{17}$, through video recording. It was transcribed, analyzed, and classified, according to Hanayama's criteria $^{12}$, by a speech-language-hearing therapist trained with recordings of subjects with CLP. In approximately $70 \%$ of the cases, the speech samples were submitted to a second assessor. There was $100 \%$ agreement between the judges regarding the classification of speech disorders. The classification used divides the speech changes into passive changes, active changes, or changes caused by deformities in the dentoalveolar and palatine structures ${ }^{12}$.

The dental occlusion characteristics were assessed with clinical examination, using the orthodontics clinical assessment sheet applied to speech-languagehearing, furnished by the Speech-Language-Hearing Program at the institution of origin. In $100 \%$ of the cases, the dental occlusion characteristics and the malocclusions were submitted to a second assessor; there was $100 \%$ agreement between the judges regarding these classifications. The types of dental occlusion changes and malocclusions assessed with this sheet are based on authors of classic books on orthodontics ${ }^{18-20}$. The speech-language-hearing therapist (author of this article) was trained to use the sheet to assess patients with CLP along with a dentist specialized in orthodontics and facial orthopedics (this article's research advisor). The photographic images of the participants' faces - anterior view, serious and smiling; left- and right-side view, serious; occlusal view of upper and lower dental arches, both isolated and in front, right side, and left side occlusion - were used to confirm the clinical findings. Both assessments used in the research have quantitative and qualitative data. The researcher was calibrated with the clinical assessment of patients accompanied by the researchers of the study who were experienced in speech-languagehearing and orthodontics.

The information collected was stored in a databank developed in Microsoft Excel 2010 and then transferred to the Statistical Package for the Social Sciences (SPSS), version 25 for Windows, in which the statistical analysis was made. The quantitative variables were described in mean and standard deviation, whereas the categorical ones were described in absolute and relative frequencies. The chi-square test, Fisher's exact test, and $t$-test were used to verify the associations between the variables at the $5 \%$ significance level and $95 \%$ confidence interval.

\section{RESULTS}

The data from the medical records of 150 participants were analyzed - 60 from the HCSA and 90 from the CERLAP/PUCRS. The final sample comprised 11 subjects who met the inclusion criteria and attended the visits during data collection. They were 6 to 10 years old; $81.8 \%$ were males; $72.7 \%$ were self-reported white, and $27.3 \%$, multiracial; $9.1 \%$ had partial unilateral left pre-incisive foramen cleft; $9.1 \%$ had partial unilateral left pre-incisive foramen cleft associated with a submucous cleft; and $82.1 \%$ had trans-incisive foramen cleft $(63.9 \%$ on the left side, $9.1 \%$ on the right side, and $9.1 \%$ bilateral).

The dental occlusion characteristics are shown in Table 1. Among the most prevalent ones, there are the tapered upper arch form, ACB, PCB, upper anterior dental crowding, tooth in palatoversion on the site of the cleft, extreme tooth rotation of the upper central incisor adjacent to the cleft, and lesions suggestive of caries. Some of these dental-occlusal changes are shown in Figures 1 and 2. An interesting intraoral finding was the prevalence of low insertion of upper lip frenulum in seven (63.6\%) individuals of the sample. 
Table 1. Dental occlusion characteristics

\begin{tabular}{|c|c|c|}
\hline CHARACTERISTICS & $\mathbf{N}$ & $\%$ \\
\hline \multicolumn{3}{|l|}{ Type of teeth } \\
\hline Deciduous & 1 & 9.1 \\
\hline Mixed & 10 & 90.9 \\
\hline \multicolumn{3}{|l|}{ Upper arch form } \\
\hline Normal & 1 & 9.1 \\
\hline Squared & 3 & 27.3 \\
\hline Tapered & 7 & 63.6 \\
\hline \multicolumn{3}{|l|}{ Upper anterior dental crowding } \\
\hline Absent & 5 & 45.5 \\
\hline Present & 6 & 54.5 \\
\hline \multicolumn{3}{|l|}{ Anterior open-bite } \\
\hline Absent & 10 & 90.9 \\
\hline Present & 1 & 9.1 \\
\hline \multicolumn{3}{|l|}{ Anterior crossbite } \\
\hline Absent & 4 & 36.4 \\
\hline Present & 7 & 63.6 \\
\hline \multicolumn{3}{|l|}{ Posterior crossbite } \\
\hline Absent & 2 & 18.2 \\
\hline Present on the same side of the cleft & 4 & 36.4 \\
\hline Present bilaterally & 5 & 45.5 \\
\hline \multicolumn{3}{|c|}{ Teeth in palatoversion on the site of the cleft } \\
\hline Absent & 4 & 36.4 \\
\hline Present & 7 & 63.6 \\
\hline \multicolumn{3}{|c|}{ Clinical absence of permanent upper lateral incisors } \\
\hline Absent & 10 & 90.9 \\
\hline Present & 1 & 9.1 \\
\hline \multicolumn{3}{|c|}{ Extreme tooth rotation of upper central incisor adjacent to the cleft } \\
\hline Absent & 5 & 45.5 \\
\hline Present & 7 & 63.6 \\
\hline \multicolumn{3}{|l|}{ Lesion suggestive of oral caries } \\
\hline Absent & 3 & 27.3 \\
\hline Present & 8 & 72.7 \\
\hline \multicolumn{3}{|l|}{ Dental restorations } \\
\hline Absent & 8 & 72.7 \\
\hline Present & 3 & 27.3 \\
\hline TOTAL & 11 & 100 \\
\hline
\end{tabular}

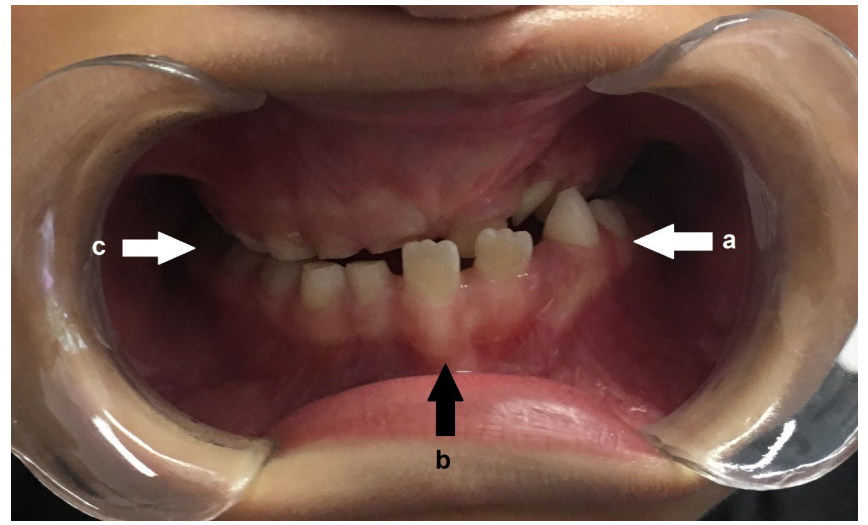

Highlighting the anterior crossbite on the left side (a), lower midline deviation to the left (b), and changed occlusal plane (c).

Figure 1. Frontal intraoral image in occlusion

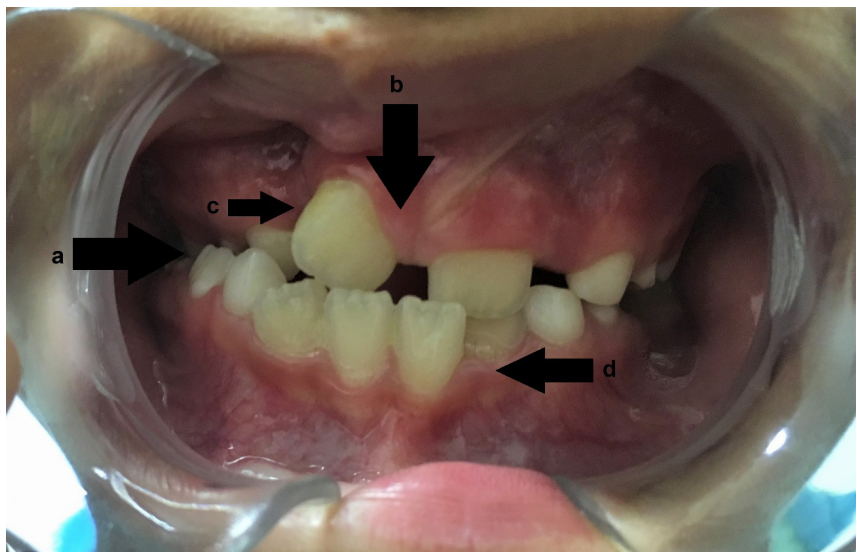

Highlighting the anterior crossbite on the right side (a), upper midline deviation to the right (b), extreme distal rotation of the upper right central incisor, adjacent to the cleft (c), and lower crowding of teeth (d).

Figure 2. Frontal intraoral image in occlusion. 
The speech changes are described in Table 2. The passive speech changes did not have a statistically significant relation to sex $(p=0.345)$, type of cleft ( $p$ $=0.345)$, ACB $(p=1)$, or PCB $(p=0.345)$. The active speech changes had no statistical difference - i.e., with sex $(p=0.491)$, type of cleft $(p=0.491)$, ACB $(p=$ $0.491)$, or PCB $(p=0.491)$. The changes caused by deformities in the dentoalveolar and palatine structures were present in $10(90.9 \%)$ subjects of the sample. The main change in this group was "other articulation point changes", present in nine $(81.8 \%)$ subjects. One of these changes is the [I] speech sound produced between the tip of the tongue and the vestibular face of the upper central incisors. Concerning passive changes - present in nine $(81.8 \%)$ subjects -, the audible nasal air escape was present in seven (63.6\%) subjects, the highest index in this group. As for the active changes, the dorsal mid-palatal stop had greater incidence, present in six (54.5\%) subjects.

Table 2. Characterization of speech changes

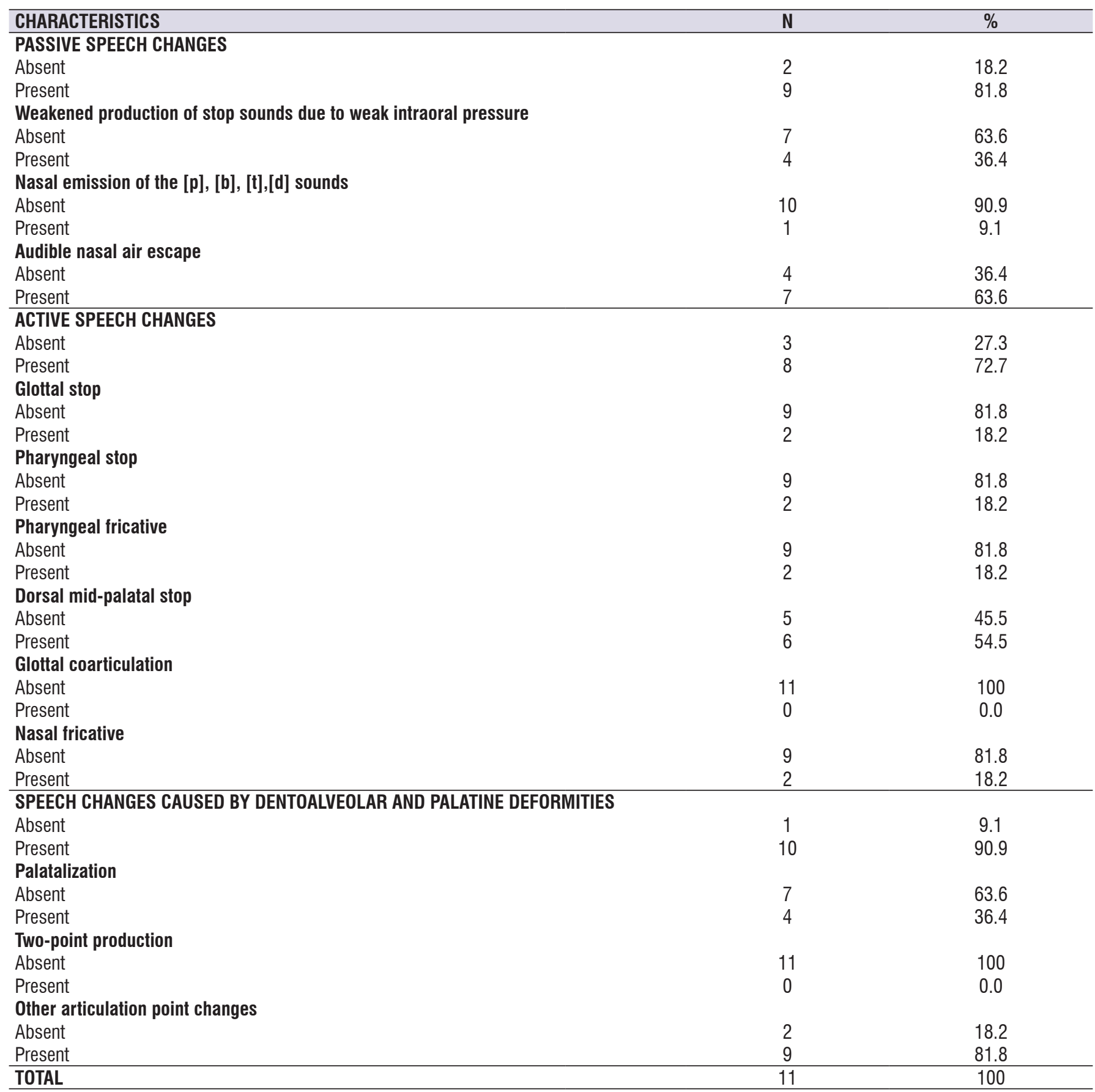


The relationship between speech and dental occlusion changes in the different types of cleft was not statistically significant. Of the nine (81.8\%) subjects with a trans-incisive foramen cleft, five $(55.5 \%)$ presented tapered upper arch form - all of whom had speech changes. The two subjects with pre-incisive foramen cleft did not have a crossbite. These data can be verified in Table 3.

Table 3. Description of type of cleft, upper arch form, most frequent dental occlusion changes, and speech changes

\begin{tabular}{ccccccccc}
\hline Subject & Type of cleft & $\begin{array}{c}\text { Affected } \\
\text { side }\end{array}$ & Upper arch form & PCB & ACB & AA & PA & DA \\
\hline 1 & Trans-incisive foramen & $\mathrm{L}$ & Tapered & $\mathrm{P}$ & $\mathrm{P}$ & $\mathrm{P}$ & $\mathrm{P}$ & $\mathrm{P}$ \\
2 & Pre-incisive foramen & $\mathrm{R}$ & Tapered & $\mathrm{A}$ & $\mathrm{A}$ & $\mathrm{P}$ & $\mathrm{P}$ & $\mathrm{A}$ \\
3 & Trans-incisive foramen & $\mathrm{L}$ & Squared & $\mathrm{P}$ & $\mathrm{P}$ & $\mathrm{P}$ & $\mathrm{P}$ & $\mathrm{P}$ \\
4 & Trans-incisive foramen & $\mathrm{L}$ & Normal & $\mathrm{P}$ & $\mathrm{P}$ & $\mathrm{P}$ & $\mathrm{P}$ & $\mathrm{P}$ \\
5 & Trans-incisive foramen & $\mathrm{L}$ & Tapered & $\mathrm{P}$ & $\mathrm{P}$ & $\mathrm{P}$ & $\mathrm{P}$ & $\mathrm{P}$ \\
6 & Trans-incisive foramen & $\mathrm{L}$ & Squared & $\mathrm{P}$ & $\mathrm{A}$ & $\mathrm{P}$ & $\mathrm{P}$ & $\mathrm{P}$ \\
7 & Trans-incisive foramen & $\mathrm{L}$ & Squared & $\mathrm{P}$ & $\mathrm{P}$ & $\mathrm{P}$ & $\mathrm{P}$ & $\mathrm{P}$ \\
8 & Trans-incisive foramen & $\mathrm{L}$ & Tapered & $\mathrm{P}$ & $\mathrm{P}$ & $\mathrm{A}$ & $\mathrm{A}$ & $\mathrm{P}$ \\
9 & Trans-incisive foramen & $\mathrm{R}$ & Tapered & $\mathrm{P}$ & $\mathrm{P}$ & $\mathrm{P}$ & $\mathrm{P}$ & $\mathrm{P}$ \\
10 & Pre-incisive foramen & $\mathrm{L}$ & Tapered & $\mathrm{A}$ & $\mathrm{A}$ & $\mathrm{A}$ & $\mathrm{A}$ & $\mathrm{P}$ \\
11 & Trans-incisive foramen & $\mathrm{B}$ & Tapered & $\mathrm{P}$ & $\mathrm{A}$ & $\mathrm{P}$ & $\mathrm{A}$ & $\mathrm{P}$ \\
\hline
\end{tabular}

Captions: $\mathrm{R}=$ Right; $\mathrm{L}=$ Left; $\mathrm{B}=$ Bilateral; $\mathrm{P}=$ Present; $\mathrm{A}=\mathrm{Absent} ; \mathrm{PCB}=$ Posterior crossbite; $\mathrm{ACB}=$ Anterior crossbite; $\mathrm{AA}=$ Active speech changes; $\mathrm{PA}=$ Passive speech changes; $D A=$ Speech changes caused by deformities in the dentoalveolar and palatine; $P=$ Present; $A=$ absent

The subjects of the research were submitted to primary lip repair surgery between 3 and 15 months old - mean, 6 months; and to primary palatoplasty between 9 and 17 months old - mean, 13 months and 12 days. No statistically significant association was found between speech and dental occlusion changes and the time of primary plastic surgeries. However, subjects without ACB were submitted to lip repair surgery at 8.8 months old on average, and subjects with $\mathrm{ACB}$, at 4.4 months on average. Hence, subjects with ACB tended to undergo primary lip repair surgery 4 months on average before those without ACB $(p=0.051)$. There was no significant difference in the time of palatoplasty between subjects with and without ACB ( $p=0.974)$. These results are shown in Table 4.

Table 4. Relationship between anterior crossbite, lip repair surgery, and palatoplasty

\begin{tabular}{cccccc}
\hline & ACB & N & Mean (months) & SD & P-value \\
\hline \multirow{2}{*}{ Lip repair surgery } & Absent & 4 & 8.8 & 4.2 & 0.051 \\
& Present & 7 & 4.4 & 2.3 & \\
\multirow{2}{*}{ Palatoplasty } & Absent & 2 & 13.5 & 0.7 & 0.974 \\
& Present & 7 & 13.4 & 2.9 & \\
\hline
\end{tabular}

Caption: $A C B=$ anterior crossbite

Statistical test: t-test $(\mathrm{p}$-value $<0.05)$ 


\section{DISCUSSION}

The results related to the type of cleft, laterality, and sex agree with what is reported in the literature ${ }^{2,10}$. The subjects in this study were mostly males, with a greater incidence of the trans-incisive foramen cleft. There were higher rates of affection on the left side, as observed in other studies ${ }^{2,10}$. The literature reports greater incidence in the East Asian population, whereas in this study it occurred among self-reported white subjects ${ }^{3}$.

The data on lesions suggestive of oral caries and the presence of dental restorations agree with the literature, which reports that children with CLP are at greater risk of developing dental caries than the same-age babies without clefts ${ }^{21}$. This situation may be associated with the difficulty in keeping proper oral hygiene, due to the dental misalignment in relation to the anatomy of the cleft area ${ }^{22,23}$. Another factor concerning the risk of oral caries is the higher rate of dental biofilm in CLP than in $\mathrm{CP}^{23}$. Furthermore, subjects with CLP usually have fewer opportunities of being instructed on oral hygiene and having professional dental cleaning ${ }^{22}$. Oftentimes, they have precarious socioeconomic conditions - such as the ones in this study -, which makes it important to provide more oral health promotion aimed at this population.

In the subjects with a trans-incisive foramen cleft, the rates of dental occlusion changes, such as PCB, were higher than those found in the literature, whose frequency is $31.7 \%{ }^{16}$. The anterior open-bite occurred in only one subject of the sample, corroborating the literature, which reports its presence in $8.3 \%$ of the CLP cases $^{16}$. Studies report that ACB results from the excessive pressure exerted by the scar tissue after lip repair surgery, as well as the maxillary retrognathia ${ }^{10}$. After lip repair surgery, the tension caused by the scar can limit the movement of the alveolar segment and restrict the maxillary development ${ }^{10}$. A negative overjet of 1 to 5 millimeters in the upper incisors on the side of the cleft is reported in the literature ${ }^{24}$.

The tapered upper dental arch form and the upper anterior dental crowding were present in the children in this study. The tapered configuration may be related to the presence of maxillary hypoplasia and palatal narrowing $^{10}$. Five of the nine subjects with transincisive foramen cleft had tapered upper arch form; all of them had speech changes, probably due to the deformities in dentoalveolar and palatine structures, as well as the PCB. It is described in the literature that maxillary hypoplasia and palatal narrowing are present in the unilateral trans-incisive foramen cleft after primary surgical interventions ${ }^{10}$. Since all the subjects with trans-incisive foramen cleft in this sample had undergone primary palatoplasty, and $36.4 \%$ of these had undergone secondary palatoplasty as well, it was not possible to relate this dental occlusion change to the time of the surgery. Moreover, among the causes of speech changes (especially those of alveolar consonants), there are dental and occlusal deviations, such as crossbite, maxillary protrusion or retrusion, dental failures, anterior teeth rotation, and ectopic teeth ${ }^{12}$. In this sample, $63.6 \%$ of the participants had extreme tooth rotation of the upper central incisor adjacent to the cleft; the same percentage had teeth in palatoversion on the site of the cleft. Dental crowding is a frequent characteristic in the segmented maxilla, related to the change in sagittal growth and transversal atresia ${ }^{25}$.

In the literature, there are various classifications of speech changes in CLP' ${ }^{12}$. Some studies tried to compile and standardize the classifications; however, there has been no single form of assessing and classifying the speech changes in these individuals so far $^{12,26}$. The researcher and the clinical speechlanguage-hearing therapist must be acquainted with terminologies currently used to describe the articulation disorders in CLP since differences in terminology reflect the time when these productions were presented in the literature ${ }^{26}$. The auditory-perceptual evaluation is the most used evaluation method to measure speech changes $^{6,27}$. Nevertheless, other methods, such as nasendoscopy, spectography, videofluoroscopy, and electropalatography, are also used to evaluate velopharyngeal dysfunction in CLP ${ }^{13,26}$.

The presence of weak intraoral pressure reported in the participants of this study agrees with the literature, which refers to the presence of this change in $30 \%$ to $44 \%$ of the subjects with CLP ${ }^{11}$. The findings related to audible nasal air escape corroborate what is exposed in the literature - i.e., that most of the subjects with corrected CLP and CP have nasal air escape ${ }^{28}$. This suggests that such children have insufficient closure of the velopharyngeal sphincter. When compared to same-age babies without CLP, none of the controls has nasal air escape ${ }^{28}$.

There was a low incidence of glottal stop among the subjects in the sample, disagreeing with the rates found in the literature ${ }^{11}$. The research findings may be related to most of these subjects' attending speechlanguage-hearing therapy since their first months of life. The dorsal mid-palatal stop was reported in six (54.5\%) 
of the subjects, which differs from what is reported in the literature - that it occurs in lower rates ${ }^{11}$.

Subjects with CLP commonly present compensatory articulation disorders. These are modifications in the production of speech sounds due to structural problems inherent to the cleft. They occur in the initial phases of speech acquisition, changing the articulation point ${ }^{26}$. Regarding this, a study showed that $72 \%$ of the children with CLP who had undergone surgery lisped when producing alveolar fricatives - which is related to dentofacial deformities ${ }^{27}$.

The literature reports an incidence of articulation disorders in $55 \%$ to $75 \%$ of the subjects with CLP ${ }^{11}$. In this study, a peculiar change of articulatory point caused by dentoalveolar and palatine deformity was the [l] speech sound produced with the tip of the tongue in contact with the vestibular face of the upper incisors. This change in articulation points can be related to the changed relationship between the maxilla and mandible, maxillary hypoplasia, and midface retrusion. The last two are common findings in subjects with clefts submitted to lip repair surgery ${ }^{10}$.

Although it was a prevalent anatomical peculiarity in the sample (63.6\%), the low insertion of the upper lip frenulum in children with CLP was not found in the literature. The positioning of the upper lip frenulum changes with growth: in the newborn, it is inserted on the palatine papilla; as the vertical dimension increases, it tends to migrate apically, being positioned at the vestibular region ${ }^{29}$. When the lip frenulum has an abnormal positioning, the person may present interincisal diastema and restricted lip movements, changing both speech and aesthetics ${ }^{29}$. Even though the change in the upper lip frenulum is not reported in subjects with CLP, a primary rhinocheiloplasty technique is proposed, which frees and completely mobilizes the lip-nose elements, including the oral mucosa and upper lip frenulum. Its results reveal good aesthetical and functional outcomes, without restrictions to facial growth $^{30}$.

The relationship between ACB and lip repair surgery found in this study suggests that, concerning dental occlusion, it would be ideal to perform lip repair surgery at around 8 months and 24 days - which is a later age than usual in most of the current surgery protocols. It is known that primary lip and palate surgeries reduce the transversal and anteroposterior measures of the maxilla, causing a high prevalence of crossbites ${ }^{8}$. Such dental occlusion findings are related to the excessive pressure exerted by the scar tissue after the lip repair surgery ${ }^{10}$. After these procedures, the maxillary growth can be affected in the horizontal, vertical, and transversal directions, possibly affecting the dental arch and occlusion ${ }^{10}$. The lip repair surgery, usually performed between 3 and 6 months of life ${ }^{5}$, improves the aesthetic, speech, and quality of life of subjects with CLP' Hence, delaying this procedure may cause changes in these functions.

A study showed that subjects submitted to palatoplasty before two years old have lower rates of articulation disorders and glottal stops when compared with those who underwent late palatoplasty - i.e., after two years old ${ }^{11}$. Nonetheless, in this study it was not possible to relate the time of primary palatoplasty to speech and dental occlusion changes because the primary palatoplasty took place on average at 13.4 months - thus, none of the 11 subjects in the sample met the criterion to be included in the group of late primary palatoplasty. In the literature, there is yet no consensus regarding the ideal age for primary palatoplasty, considering a range of surgical techniques and protocols found. However, it is established that the palatoplasty must be performed before 24 months. After this period, it is considered late ${ }^{11}$.

The primary plastic surgeries in this sample were performed at an adequate age, which shows that these subjects had early access to the outpatient centers hence, the surgical procedures were performed at an opportune time. There is a report in the literature that presents the mean of primary palatoplasty close to this one ${ }^{28}$. Throughout the years, the surgical protocols have evolved and improved their organization regarding the results they obtain. This led the subjects to start early the follow-up for surgery; consequently, the plastic surgeries have been taking place at an adequate time, according to the established protocols ${ }^{5}$.

It should be mentioned that it was not possible, in this research, to standardize the technique employed in primary plastic surgeries because of the characteristics of the outpatient centers where the collection was made. Moreover, there were few subjects in the sample, which may limit the generalization of the results obtained in the study. There are few standardized, methodologically replicable, randomized studies approaching aspects of speech and dental occlusion changes in subjects with CLP. It is expected, though, based on what was exposed in this paper, that further research will be fomented and encouraged, centered on the relationship between phonetic aspects of speech production and structural changes present in 
subjects with CLP - especially regarding the relationships between anterior and posterior crossbites, lip repair surgery, and changes in articulation point.

\section{CONCLUSION}

The associations between speech and dental occlusion changes, and between these and the time of primary plastic surgery were not statistically significant. It is known that lip repair surgery is ideally performed at an early age to favor oral function and aesthetics. However, this study's results showed that the subjects who had been submitted to such a surgery at the mean age of 4 months tended to have an anterior crossbite. Further studies with larger samples are necessary to evaluate these associations.

\section{ACKNOWLEDGMENT}

Gratitude is extended to Dr. Renato Tetelbom Stein for making it possible to conduct the research at the Hospital São Lucas at Pontifícia Universidade Católica do Rio Grande do Sul (HSL - PUCRS).

\section{REFERENCES}

1. Paniagua LM, Collares MVM, Costa SSD. Comparative study of three techniques of palatoplasty in patients with cleft of lip and palate via instrumental and auditory-perceptive evaluations. Intl Arch Otorhinolaryngol. 2010;14(1):18-31.

2. Souza J, Raskin S. Clinical and epidemiological study of orofacial clefts. J Pediatr. 2013;89(2):137-44.

3. Allagh KP, Shamanna BR, Murthy GV, Ness $A R$, Doyle P, Neogi SB et al. Birth prevalence of neural tube defects and orofacial clefts in India: a systematic review and meta-analysis. PLoS ONE. 2015;10(3):1-15.

4. Al-Kharboush GH, Al-Balkhi KM, Al-Moammar $\mathrm{K}$. The prevalence of specific dental anomalies in a group of Saudi cleft lip and palate patients. Saudi Dent J. 2015;27(2):75-80.

5. Alonso N, Tanikawa DYS, Lima Junior JE, Ferreira MC. Comparative and evolutive evaluation of attendance protocols of patients with cleft lip and palate. Rev Bras Cir Plást. 2010;25(3):434-8.

6. Palandi BBN, Guedes ZCF. Aspectos da fala de indivíduos com fissura palatina e labial, corrigida em diferentes idades. Rev. CEFAC. 2011;13(1):8-16.
7. Schilling GR, Cardoso MCAF, Maahs MAP. Effect of palatoplasty on speech, dento-occlusal issues and upper dental arch in children and adolescents with cleft palate: a literature review. Rev. CEFAC. 2019;21(6):e12418.

8. Pedro RDL, Tannure PN, Antunes LAA, Costa MDC. Dental abnormalities in patients with cleft lip and palate: literature review. Rev Odontol Univ Cid São Paulo. 2010;22(1):65-9.

9. HRAC-USP. Etapas e condutas terapêuticas: fissuras labiopalatinas, anomalias craniofacias, saúde auditiva e síndromes. [Manual]. Bauru: Universidade de São Paulo; 2018.

10. Kongprasert T, Winaikosol K, Pisek A, Manosudprasit A, Manosudprasit A, Wangsrimongkol $B$ et al. Evaluation of the effects of cheiloplasty on maxillary arch in UCLP infants using three-dimensional digital models. Cleft Palate Craniofac. 2019;20(10):1-7.

11. Menegueti Kl, Mangilli LD, Alonso N, Andrade CRFD. Speech profile of patients undergoing primary palatoplasty. CoDAS. 2017;29(5):1-10.

12. Hanayama EM. Communication disorders in patients with sequels of cleft lip and palate. Rev Bras Cir Craniomaxilofac. 2009;12(3):118-24.

13. Kummer AW. Cleft palate and craniofacial anomalies: the effects on speech and resonance. 3rd edition. New York: Delmar Cengage Learning; 2013.

14. Andreoli MA, Yamashita RP, Trindade-Suedam IK, Fukushiro AP. Speech intelligibility after primary palatoplasty: listener perception. Audiol Commun Res. 2016;21:1-7.

15. Pereira AC, Nishiyama CK, Pinto LDC. Dental anomalies in individuals with unilateral cleft lip and palate and endodontic treatment. RFO UPF. 2013;18(3):328-34.

16. Sabino MFPA, Katz CRT, Bezerra NSDL, Monteiro JLGC. Occurrence of oral habits and malocclusion in children with cleft lip and/or palate. Pesq Bras Odontoped Clin Integr. 2012;12(2):237-43.

17. Marchesan IQ. Protocolo de avaliação do frênulo da língua. Rev. CEFAC. 2010;12(6):977-89.

18. Ferreira FV. Diagnóstico e planejamento clínico. 7a ed. São Paulo: Artes Médicas; 2008.

19. Moyers RE. Ortodontia. 4a ed. Rio de Janeiro: Guanabara-Koogan, 1991.

20. Proffit WR. Ortodontia Contemporânea. 5aed. Rio de Janeiro: Elsevier, 2013. 
21. Sundell AL, Ullbro C, Marcusson A, Twetman S. Comparing caries risk profile between 5and 10- year-old children with cleft lip and/or palate and non-cleft controls. BMC Oral Health. 2015;15(85):2-6.

22. Funahashi K, Shiba T, Watanabe T, Muramoto K, Takeuchi $\mathrm{Y}$, Ogawa $\mathrm{T}$ et al. Functional dysbiosis within dental plaque microbiota in cleft lip and palate patients. Prog Orthod. 2019;20(11):1-10.

23. Mutthineni RB, Nutalapati R, Kasagani SK. Comparison of oral hygiene and periodontal status in patients with clefts of palate and patients with unilateral cleft lip, palate and alveolus. J Indian Soc Periodontol. 2010;14(4):236-40.

24. Disthaporn S, Suri S, Ross B, Tompson B, Baena $D$, Fisher $D$ et al. Incisor and molar overjet, arch contraction, and molar relationship in the mixed dentition in repaired complete unilateral cleft lip and palate: A qualitative and quantitative appraisal. Angle Orthodontist. 2017;87(4):603-9.

25. Garib DG, Almeida AM, Lauris RCMC, Peixoto AP, Silva Filho OG. Tratamento ortodôntico de pacientes com fissuras labiopalatinas: protocolo do HRAC/USP. In: Curso de Anomalias Congênitas Labiopalatinas, 44, 2011, Bauru. Anais. Bauru, 2011.

26. Marino VCC, Dutka JCR, Pegoraro-Krook MI, Lima-Gregio AM. Articulação compensatória associada à fissura de palato ou disfunção velofaríngea: revisão de literatura. Rev. CEFAC. 2012;14(3):528-43.

27. Whitaker ME, Dutka JDCR, Lauris RDMC, Pegoraro-Krook MI, Marino VCDC. Occurrence of lisping in voiced and unvoiced fricatives in children with operated cleft lip and palate. Rev. CEFAC. 2014;16(4):1222-30.

28. Bruneel L, Bettensa K, Bodt MD, Roche N, Bonte K, Lierde KV. Speech outcomes following Sommerlad primary palatoplasty: results of the Ghent University Hospital. J Communi Disord. 2018;72:111-21.

29. Duarte DA, Bönecker M, Corrêa FNP, Corrêa MSNP. Cirurgia bucal em pacientes pediátricos. In: Corrêa MSNP, editor. Odontopediatria na primeira infância. 2eed. São Paulo: Santos. 2005. p. 629-44.

30. Tanikawa DYS, Alonso N, Rocha DL. Primary rhinocheiloplasty modification for unilateral cleft lip patients. Rev Bras Cir Plást. 2010;25(1):30-7. 